\title{
Supply chain coordination with buyback contract considering loss aversion
}

\author{
Guangxing Wei, Xin Deng
}

\author{
School of Management, Chongqing Jiaotong University
}

\begin{abstract}
In this paper, we study the buyback contract of a supply chain system including a supplier and a loss-averse retailer. The buyback contract was divided into the credit for all unsold goods and the credit for a partial return of goods. And then the paper models the two cases and carries out numerical simulation analysis. The results show that when the retailer is loss averse, the supply chain system is able to achieve coordination, the buyback price is an increasing, and buyback ratio is an increasing, while the wholesale price is decreasing function of the loss aversion of the retailer.
\end{abstract}

Key words: Supply chain coordination; buyback contract; loss-aversion

\section{Introduction}

Nowadays, the buyback contract is widely used in the decentralized supply chain in which the supplier is the decision-making body, in order to alleviate or eliminate the "double marginalization effect". There are many group buying sites on the network today, such as Groupon, 24 Ticket. Due to the large number of the sites, the competition is very intense between the Group buying sites, and many Group buying sites promised unconditional refund for the consumer who unused coupons in order to increase sales. This marketing tool is actually a buy back policy. But the failure of buyback contract coordination is often found in practical applications. According to national agricultural products and agricultural materials price quotes system monitored by the Xinhua News Agency, meat prices, vegetables and fruit prices are all rising. The reason is that researchers have ignored consumer's loss aversion preferences. In the experimental study of Schweitzer and Cachon (2000), buyers determine the purchase quantity according to the given price and demand distribution, and they found that the retailer's ordering behavior is not consistent with the ordering behavior in the traditional assumption of risk neutral to maximize the expected profit. Facts have proved that the loss aversion preferences exist and influence the behavior of decision-making. Feng et al. (2011) stressed the need for the introduction of the risk tolerance in experimental studies in contrasting the differences of ordering strategy between China and the United States. The article will analyze the supply chain including the decision makers with loss aversion preferences and develops the buyback contract.

Pasternack (1985) is the first one to discuss the return policy, and he researched a model on perishable products of fixed price, and applied optimal pricing and returning policy to ensure channel coordination, although partial return policy with the full price can ensure channel coordination in single retailers and single supplier system, which is not optimal for Multi-retailers system, because the uniform wholesale price of unity and buyback price can not ensure the fairness of the profit division (Tasy, 2001). Charles (2009) considered the risk aversion to model the decision-making behavior of manager by a newsvendor model, and he found that optimal order quantity increase as the wholesale price increase, but decrease as retail price increase. Later, Charles (2010) expanded the standard risk neutral newsvendor model to two-stage supply chain of a risk neutral supplier and more loss averse retailers, and he proved if suppliers distribute the production according to each retailer's order quantity, then only one solution can achieve Nash equilibrium, and risk aversion can reduce the total order quantity of retailer, especially when the risk aversion degree was high enough, total inventory level in decentralized supply chain was lower than the centralized one. Luca Colombo (2012) considered the pricing problem of a risk aversion retailer under uncertainty demand, and the price announced by risk-averse retailer was lower than that by risk neutral retailer. Arcelus (2012) evaluated the pricing and ordering strategies of retailers of different risk attitudes in the newsvendor model. Yang and Guo (2005) established different coordination models in different risk preference combination of suppliers and retailers, and obtained the Pareto optimal solutions. Lin and Zhang (2010) discussed the effect of buyback price and market uncertainty on decision variables and the objective function, and they showed that the buyback price can influence the inventory decision obviously by numerical simulation when the market demand meet the second-order stochastic dominance 
criteria.

This paper will buyback contract of a supply chain system including a supplier and a loss-averse retailer, and the supplier is dominant in the supply chain. The buyback contract can be classified as the credit for all unsold goods and the credit for a partial return of goods. In full buyback contract, buyback price should increase as the loss-aversion increase, while wholesale prices should decrease with the loss-aversion rising, so as to achieve the coordinated supply chain. In part buyback contract, buyback proportion should increase as the loss-aversion increase, and wholesale prices should decrease with the loss-aversion rising.

\section{Denotation}

$D>0$ : demand during the selling season, $\mu=E(D), \mu=\int_{0}^{\infty} x f(x) d x$.

$F(x)$ : The distribution function of demand, and it is differentiable, strictly increasing $F(0)=0 . \bar{F}(x)=1-F(x)$.

$f(x)$ : The density function of demand;

$p:$ The retail price;

$w$ : The wholesale price;

$c:$ The supplier's production cost per unit, $p>w>c$

$q$ : The order quantity of the retailer;

$b$ : The price that the supplier pays the retailer for the remaining product, $b<w$.

$n$ : The proportion of the remaining product bought by supplier at the end of the season, $n<1$

$\lambda_{r}:$ The loss aversion coefficient of retailer;

$S(q)$ : The expected sale, $S(q)=\int_{0}^{q} x f(x) d x+\int_{q}^{\infty} q f(x) d x=\int_{0}^{q} \bar{F}(x) d x$

$I(q):$ The expect inventory of the retailer, $I(q)=q-S(q)$

$\Pi_{T}$ : The supply chain's profit function, $\Pi_{T}=p S(q)-c q=p \int_{0}^{q} \bar{F}(x) d x-c q$

Obviously, optimal order quantity of the supply chain is

$q_{T}^{*}=\bar{F}^{-1}\left(\frac{c}{p}\right)=F^{-1}\left(\frac{p-c}{p}\right)$

Supply chain coordination means that the supplier can provide a proper contract to the retailer to make the order quantity equal to $q_{T}^{*}$, so as to achieve the maximum total profit of the supply chain. Besides, we will assume the net salvage value of product is 0 and shortage condition is not referred.

\section{Buyback contract}

\subsection{Full buyback contract}

In full buyback contract, supplier sells products to retailer in wholesale price $w$, supplier buy back the residual good in $b$.

(1) The retailer is risk-neutral

The profit of risk-neutral retailer is $\Pi_{r}(q, w, b)=(p-b) \int_{0}^{q} \bar{F}(x) d x-(w-b) q$ 
For $q_{r}^{*}=\arg \max _{q} \Pi_{r}(q, w, b)$, i.e. $\bar{F}\left[q_{r}^{*}(q, w, b)\right]=\frac{w-b}{p-b}$, so $q_{r}^{*}(q, w, b)=\bar{F}^{-1}\left(\frac{w-b}{p-b}\right)$

To achieve supply chain coordination, the wholesale price $w$ and buyback price $b$ must meet $\frac{w-b}{p-b}=\frac{c}{p}$. So there is certain $0<\lambda<1$ subjected to $p-b=\lambda p$ and $w-b=\lambda c$, and we can get $\Pi_{r}(q, w, b)=\lambda p S(q)-\lambda c q$, i.e.

$\Pi_{r}(q, w, b)=\lambda \Pi_{T}(q)$

To sum up, expected profit of retailer is a linear function of profit in centralized supply chain under full buyback contract, and while in the pursuit of the maximum expected profit of its own, the retailer also achieve the maximum expected profit of the supply chain.

(2) The retailer is loss aversion

In the management practice, risk attitude will affect the optimal decisions. There are many uncertainties in supply chain management, so decision-makers will be faced with the problem of risk appetite. Compared to large suppliers, small and medium-sized retailers are loss aversion.

The utility function in loss aversion can be denoted as $\quad, \quad U(W)=\left\{\begin{array}{l}W \quad \begin{array}{l}W \geq 0 \\ \lambda W\end{array} \quad W<0\end{array}\right.$, where $x<\frac{w-b}{p-b} q, p x-w q+(q-x) b=(p-b) x-(w-b) q<0$, so

$$
\begin{aligned}
U_{r}\left(b, \lambda_{r}\right)= & \lambda_{r} \int_{0}^{\frac{w-b}{p-b} q}[(p-b) x-(w-b) q] f(x) d x+\int_{\frac{w-b}{p-b} q}^{q}[(p-b) x-(w-b) q] f(x) d x \\
& +\int_{q}^{\infty}(p-w) q f(x) d x \\
= & (p-w) q-(p-b) \int_{\frac{w-b}{p-b} q}^{q} F(x) d x-\lambda_{r}(p-b) \int_{0}^{\frac{w-b}{p-b} q} F(x) d x
\end{aligned}
$$

The optimal order quantity of retailer is

$$
q_{r}^{*}\left(b, \lambda_{r}\right)=(p-w) q-(p-b) \int_{\frac{w-b}{p-b} q}^{q} F(x) d x-\lambda_{r}(p-b) \int_{0}^{\frac{w-b}{p-b} q} F(x) d x
$$

So the first derivation of $q$ is

$$
\frac{\partial U_{r}\left(b, \lambda_{r}\right)}{\partial q}=(p-w)-\left(\lambda_{r}-1\right)(w-b) F\left(\frac{w-b}{p-b} q\right)-(p-b) F(q)
$$

If $q_{r}^{*}\left(b, \lambda_{r}\right)$ meet $\frac{\partial U_{r}\left(b, \lambda_{r}\right)}{\partial q}=0, q_{r}^{*}\left(b, \lambda_{r}\right)$ is the optimal order quantity of retailer, and $q_{r}^{*}\left(b, \lambda_{r}\right)=q_{T}^{*}$, then the supply chain can be achieved coordination.

Proposition 1: If the retailer is loss aversion, the supply chain can achieve coordination with the proper wholesale price $w$ and buyback price $b$, under the full buyback contract. 
Proof: If $b=0$, supplier will not buyback the goods remaining at the end of the season, so the utility function of the retailer is denoted as:

$U_{r}\left(w, \lambda_{r}\right)=\lambda_{r} \int_{0}^{\frac{w}{p} q}(p x-w q) f(x) d x+\int_{\frac{w}{p} q}^{q}(p x-w q) f(x) d x+\int_{q}^{\infty}(p-w) q f(x) d x$

First order condition is:

$\frac{\partial U_{r}\left(w, \lambda_{r}\right)}{\partial q}=(p-w)-p F(q)-\left(\lambda_{r}-1\right) w F\left(\frac{w}{p} q\right)=0$

When $\lambda_{r}=1, \quad F(q)=\frac{p-w}{p}$, i.e. $\left.q_{r}^{*}\left(w, \lambda_{r}\right)\right|_{\lambda_{r}=1}=F^{-1}\left(\frac{p-w}{p}\right)<q_{T}^{*}=F^{-1}\left(\frac{p-c}{p}\right)$

If $b=w$, then $\left.q_{r}^{*}\left(b, \lambda_{r}\right)\right|_{b=w}=F^{-1}(1)>q_{T}^{*}=F^{-1}\left(\frac{p-c}{p}\right)$. For $\frac{\partial U_{r}\left(b, \lambda_{r}\right)}{\partial q}$ is continuous, there will be a certain point $b^{*}(w)$ in $(0, w)$ achieving $q_{r}^{*}\left(b, \lambda_{r}\right)=q_{T}^{*}$

Comparing against the situation that retailer is risk neutral, we can draw the conclusion that in full buyback contract, to make the supply chain coordination, the buyback price $b$ should higher than the price when retailer is risk neutral, wholesale prices $w$ should be less than the price when retailer is risk neutral.

\subsection{Part buyback contract}

In part buyback contract, supplier sells products to retailer in wholesale price $w$, and then retailer sells goods to customers in retail price $p$. Finally, supplier buy back the residual good in a certain proportion of $w$.

(1) The retailer is risk-neutral

The expected profit of the retailer is:

$$
\Pi_{r}(q, w, n)=\int_{0}^{q}[p x-w q+n(q-x) w] f(x) d x+\int_{q}^{\infty}(p-w) q f(x) d x
$$

The optimal order quantity of retailer is

$$
q_{r}^{*}(q, w, n)=\arg \max _{q} \Pi_{r}(q, w, n)=(p-w) q-p \int_{0}^{q} F(x) d x+n w \int_{0}^{q} F(x) d x
$$

Let first order derivative is zero, $\quad \frac{\partial \Pi_{r}(q, w, n)}{\partial q}=(p-w)-p F(q)+n w F(q)=0 \quad$, we $\quad$ can get $q_{r}^{*}(q, w, n)=F^{-1}\left(\frac{p-w}{p-n w}\right)$. In order to coordinate the supply chain, the wholesale price $w$ and buyback proportion $n$ must meet $n^{*}=\frac{p w-p c}{p w-w c}$. Obviously, The optimal buyback proportion $n$ is the increasing function of wholesale price $w$.

(2) The retailer is loss aversion

The expected utility of the retailer is: 
$U_{r}\left(n, \lambda_{r}\right)=(p-w) q-\lambda_{r}(p-n w) \int_{0}^{\frac{(1-n) w q}{p-n w}} F(x) d x-(p-n w) \int_{\frac{(1-n) w q}{p-n w}}^{q} F(x) d x$

So $q_{r}^{*}\left(n, \lambda_{r}\right)=\arg \max _{q} U_{r}\left(n, \lambda_{r}\right)$, by the first order condition, we can get proposition 2 .

$$
\frac{\partial U_{r}\left(n, \lambda_{r}\right)}{\partial q}=(p-w)-(p-n w) F(q)-\left(\lambda_{r}-1\right)(1-n) w F\left(\frac{(1-n) w}{p-n w} q\right)=0
$$

Proposition 2: If the retailer is loss aversion, the supply chain can achieve coordination with the proper wholesale price $w$ and buyback price $b$, under the part buyback contract.

Proof: similar to proposition 1 , it is easy to prove.

Comparing with the situation where the retailer is risk neutral, we can conclude that to make the supply chain coordination, the buyback proportion $n$ should be higher than the proportion when retailer is risk neutral in part buyback contract, and wholesale prices $w$ should be less than the price when retailer is risk neutral.

\section{Numerical example}

In order to give a more direct reflection, we make a numerical analysis by Matlab 7.0, and the parameters of the perishable goods are as follow: $p=100, c=40, F \sim\left(100,20^{2}\right)$.

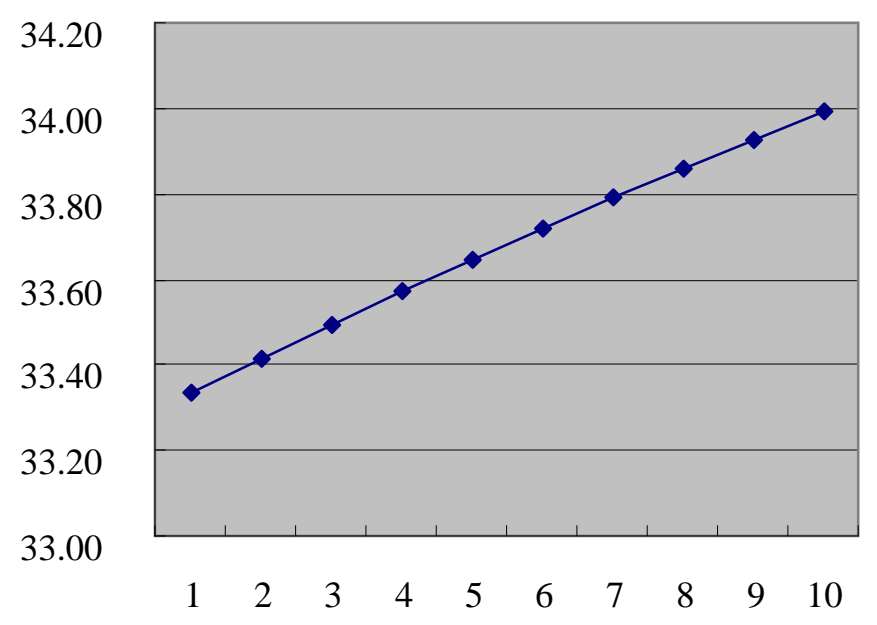

Fig.1 The relation between $b$ and $\lambda_{r}$, when $w=60$

From fig.1, in order to coordinate the supply chain, buyback price $b$ should increase as loss aversion coefficient $\lambda_{r}$ increase, and $b$ is the increasing function of the retailers loss-aversion.

If $b=33$, Substituting the parameters into the model of this article gives Table 2 . 


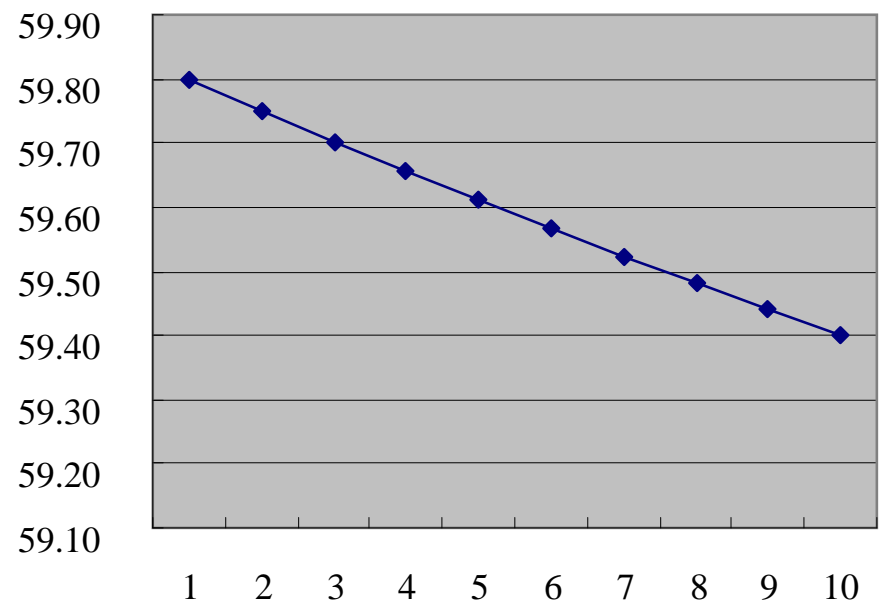

Fig. 2 The relation between $w$ and $\lambda_{r}$, when $b=33$

From fig.2, in order to coordinate the supply chain, wholesale price $w$ should decrease as loss aversion coefficient $\lambda_{r}$ increase, and the wholesale price is the decreasing function of the retailers loss-aversion.

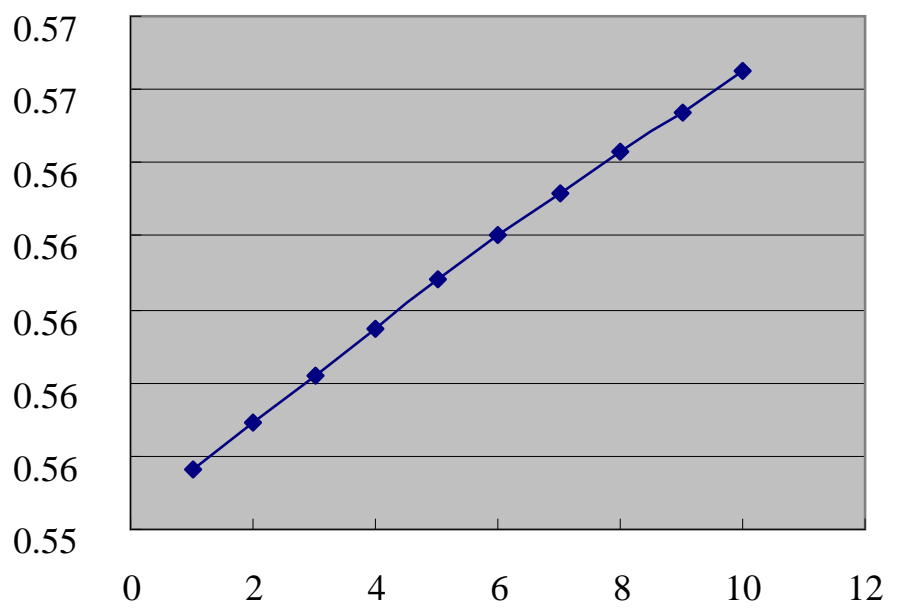

Fig. 3 The relation between $n$ and $\lambda_{r}$, when $w=60$

From fig.3, buyback proportion $n$ should increase with the increase of the retailer's loss aversion coefficient $\lambda_{r}$, so as to coordinate the supply chain. When retailers are risk neutral, buyback proportion $n$ is the minimum, i.e., buyback proportion is the increasing function of the loss aversion.

\section{Conclusion}

Most previous research of supply chain contract was based on assumption that the decision subject is risk neutral. In reality, the risk attitudes are different. Because retailers face on inevitable risk of uncertainty demand and price dropping, we study the buyback contract of a supply chain system composed of a supplier and a loss-averse retailer. The buyback contract was divided into the credit for all unsold goods and the credit for partial returned goods. By numerical analysis, we get the 
conclusion that when the retailer is loss aversion, the supply chain system can achieve coordination. In the full buyback contract, the buyback price should be higher than the price when retailer is risk neutral, while wholesale prices should be less than the price when retailer is risk neutral, so buyback price is the increasing function of loss aversion of the retailer, while wholesale price is the decreasing function of that. In the part buyback contract, the buyback proportion should be higher than the proportion when retailer is risk neutral, wholesale price should be less than the price when retailer is risk neutral, so buyback proportion is an increasing function of loss aversion of the retailer, wholesale price is a decreasing function of loss aversion of the retailer.

This paper only considered the buyback contract of a supply chain system composed of a supplier and a loss-averse retailer. Further research can be expanded to the situation, a supplier and more retailers or more suppliers and more retailers situation under asymmetric information, which is more suitable for real situation.

\section{References}

[1] M. E Schweitzer, G. P. Cachon. Decision bias in the newsvendor problem with a known demand distribution: experimental evidence [J]. Management Science, 2000, 46(3): 404-420.

[2] T. Feng, L. R Keller, X. Zhang. Decision making in the newsvendor problem: a cross natural laboratory study [J]. Omega, 2011, 39(1): 41-50.

[3] Andy. Managing retail channel overstock: Markdown money and return policies [J]. Journal of Retailing, 2001, 77(4): 457-492.

[4] X. C. Wang, S. Webster, N. C. Suresh, Would a risk-averse newsvendor order less at a higher selling price? [J]. European Journal of Operational Research, 2009,196(2): 544-553.

[5] X. Wang. The loss-averse newsvendor problem [J].International Journal of Production Economics, 2010, 124(2):448-452.

[6] L. Colombo, P. Labrecciosa. A note on pricing with risk aversion [J]. European Journal of Operational Research, 2012, 216(1): 252-254.

[7] F. J. Arcelus, S. Kumar. Risk tolerance and a retailer's pricing and ordering policies within a newsvendor framework [J].Omega, 2012, 40(2):188-198.

[8] L. Yang, Q. Guo. Research on supply chain coordination under various risk attitude portfolios [J].Management sciences in China, 2005, 18(5):7-10.

[9] Z. B. Lin, Q. S. Zhang. Supply chain model with buyback contract under risk averse assumption [J]. Forecasting, 2010, 29(6):52-56. 